\title{
Erratum to: Exploring diversity of Erwinia amylovora population in Serbia by conventional and automated techniques and detection of new PFGE patterns
}

Milan Ivanović • Aleksa Obradović •

Katarina Gašić • Gerald V. Minsavage •

Ellen R. Dickstein • Jeffrey B. Jones

Accepted: 4 July 2012 /Published online: 27 July 2012

(C) KNPV 2012

Erratum to: Eur J Plant Pathol

DOI 10.1007/s10658-011-9926-8 and

DOI 10.1007/s10658-012-9950-3

This article was erroneously published twice in Vol. 133, issue 3 pages: $545-557$ DOI: $10.1007 / \mathrm{s} 10658$ 011-9926-8 \& pages: 715-727 DOI: 10.1007/s10658012-9950-3.

This erratum acknowledges both articles as the same publication.

The online version of the original article can be found at http:// dx.doi.org/10.1007/s10658-011-9926-8.

M. Ivanović $(\bowtie) \cdot A$. Obradović $\cdot K$. Gašić

Faculty of Agriculture, Department of Plant Pathology,

University of Belgrade,

Belgrade, Serbia

e-mail: milanivanovic007@yahoo.com

G. V. Minsavage · E. R. Dickstein · J. B. Jones Plant Pathology Department, University of Florida, Gainesville, FL, USA 